\title{
Chlorophyll Breakdown as Seen in Bananas: Sign of Aging and Ripening - A Mini-Review
}

\author{
Thomas Müller Bernhard Kräutler \\ Institute of Organic Chemistry and Centre of Molecular Biosciences, University of Innsbruck, Innsbruck, Austria
}

\section{Key Words}

Apoptosis - Cell death - Fluorescence - Fruit - Musa

acuminata $\cdot$ Senescence

\begin{abstract}
The ripening of bananas is seen by a characteristic change of their color from deep green to bright yellow. Likewise, their over-ripening and eventual rotting are accompanied by the appearance of an unappetizing brown. Chlorophyll breakdown is a major contributor to the visual signs of these processes in bananas. Outlined here are the basic structures of chlorophyll catabolites in higher plants, with particular reference to ripening and aging bananas. In these fruits, unique fluorescent chlorophyll catabolites accumulate and give rise to their fascinating blue luminescence.
\end{abstract}

Copyright $\odot 2010$ S. Karger AG, Basel

\section{Introduction}

The seasonal appearance and disappearance of the green plant pigments in deciduous trees and in fruits belong to the most colorful and fascinating natural phenomena. Indeed, chlorophyll metabolism probably is the most visual sign of life on earth, and can even be observed from outer space [1]. However, only within the last 2 decades has chlorophyll breakdown in plants begun to reveal some of its mysteries (fig. 1) [1-6].

\section{KARGER}

Fax +4161306 1234

E-Mail karger@karger.ch

www.karger.com
(C) 2010 S. Karger AG, Basel

0304-324X/11/0576-0521\$38.00/0

Accessible online at:

www.karger.com/ger
This contribution reviews chlorophyll breakdown in higher plants, with emphasis on recent studies with ripening and aging bananas $[7,8]$. The discovery of the blue luminescence of bananas and identification of chlorophyll catabolites as its molecular origin have suggested fluorescent chlorophyll breakdown products to be useful molecular markers for noninvasive studies of aging and ripening. These findings also call for further exploration of the still hypothetical biological roles of chlorophyll catabolites in higher plants [7-9].

\section{Chlorophyll Catabolites in Senescent Leaves and Ripening Fruit}

Colorless and Nonfluorescent Chlorophyll Catabolites in Leaves

The longstanding puzzle of the colorful disappearance of the chlorophylls only cleared up when colorless breakdown products were taken into closer consideration [1-3, 10]. Work by Kräutler and colleagues [1-3] and Matile et al. $[10,11]$ led to the first identification of a colorless tetrapyrrole that had the structural hallmarks of a catabolite of chlorophyll. This compound was obtained from senescent leaves of barley (Hordeum vulgare) and was characterized as a $3^{1}, 3^{2}, 8^{2}$-trihydroxy-1,4,5,10,15,20- $(22 H, 24 H)$ octahydro- $13^{2}$-[methoxycarbonyl]-4,5-dioxo-4,5-seco-phyto-porphyrinate [2]. It was later classified as a 'nonfluorescent' chlorophyll catabolite (NCC) and was

Univ_-Prof. Dr. Berhard Kräutle

Institute of Organic Chemistry and Centre of Molecular Biosciences University of Innsbruck, Innrain 52a

AT-6020 Innsbruck (Austria)

Tel. +43512 507 5200, Fax +43 512507 2892, E-Mail bernhard.kraeutler@ uibk.ac.at 


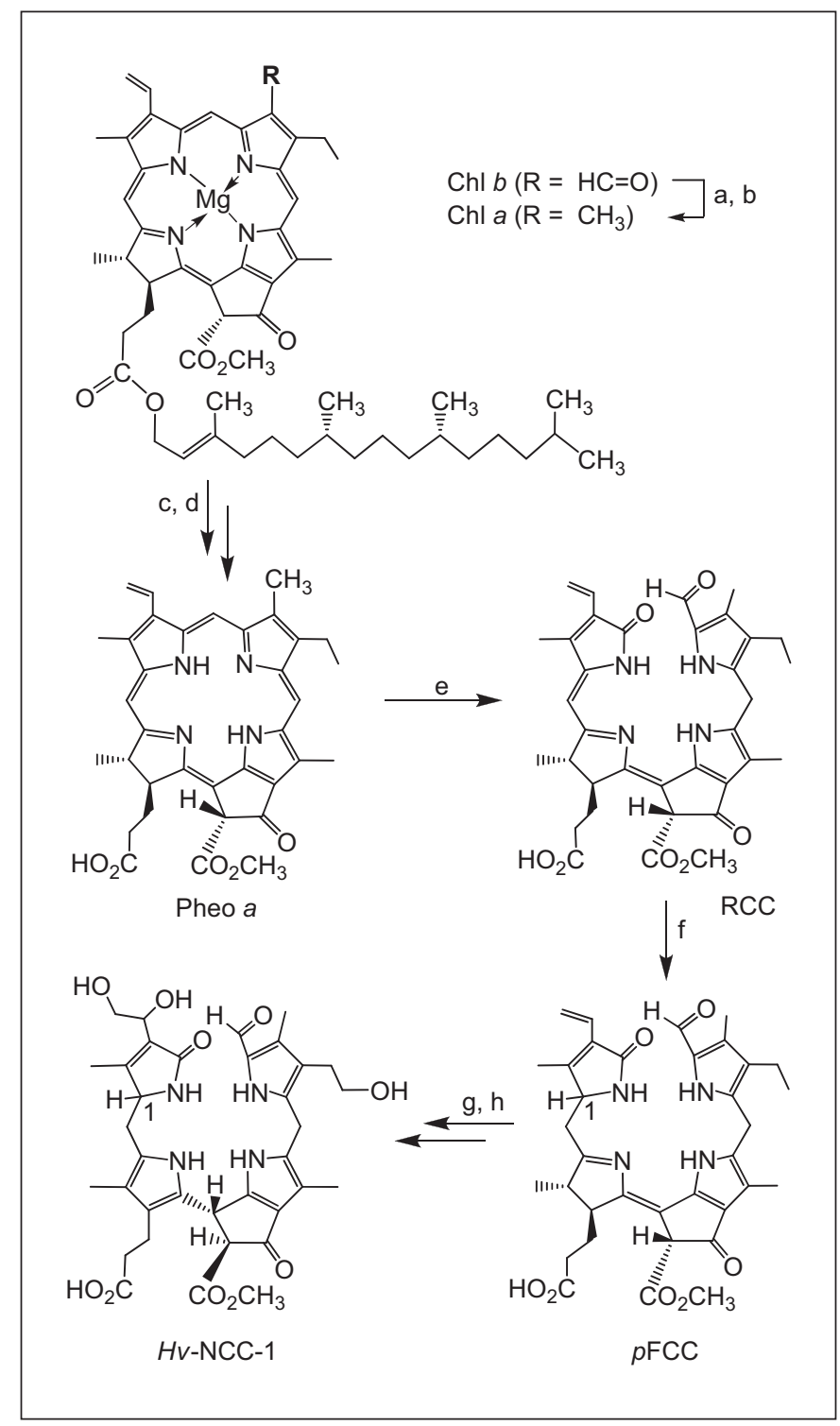

Fig. 1. Outline of chlorophyll breakdown in senescent higher plants with reference to (suggested) relevant enzyme activities [1, 3-6]. Chlorophylls [Chl $a\left(\mathrm{R}=\mathrm{CH}_{3}\right)$ or $\mathrm{Chl} b(\mathrm{R}=\mathrm{CH}=\mathrm{O})$ ] are degraded by catabolic enzymes in the chloroplast $(\mathrm{a}, \mathrm{b}=\mathrm{Chl} b$ reductase, hydroxymethyl-Chl $a$ reductase; $c, d=$ magnesium dechelatase, pheophytinase) to pheophorbide $a$ (Pheo $a$ ) and then (by e $=$ Pheo $a$ oxygenase) to 'red' chlorophyll catabolite (RCC), which is reduced (by $\mathrm{f}=\mathrm{RCC}$ reductase) to the $p$ FCC. FCCs are exported from the chloroplast into the cytosol, where they may be further modified enzymatically (g). Most FCCs are then imported into the vacuole, where $(\mathrm{h})$ their isomerization to NCCs occurs, such as to $H v$-NCC-1. named $H v$-NCC-1 (1) (fig. 1) [1]. $H v$-NCC-1 is a linear tetrapyrrole, which is colorless due to deconjugation of the four pyrrole units. Its structure thus gave the first hints as to the changes that happen to chlorophylls during their breakdown in higher plants: it indicated oxygenolytic opening of the macroring of chlorophyll $a$ at the northern meso-position and loss of both the central magnesium ion and the lipophilic phytol group.

In the meantime, NCCs have been identified in senescent leaves from a variety of vascular plants and their basic structural pattern has been established: it involves four deconjugated pyrrolic units in a substituted formyl-bilane, whose $\alpha$-formyl group is derived from the former $\alpha$-meso carbon of chlorophyll $a$. In solution, NCCs display a characteristic UV/Vis absorption maximum near $320 \mathrm{~nm}$, which is due to the $\alpha$-formyl pyrrole moiety $[5,12]$.

\section{Blue Fluorescent Catabolites of Chlorophyll}

In the course of the elucidation of the chlorophyll breakdown path, the eventual identification of the direct precursors of the NCCs as 'fluorescent' chlorophyll catabolites (FCCs) was a further major breakthrough [13]. Minute amounts of fluorescent compounds were observed early in senescent leaves, due to an easily detected blue emission (near $450 \mathrm{~nm}$ ) [10]. However, they occurred only fleetingly during leaf senescence and were suggested to be intermediate chlorophyll breakdown products. The first structural characterization of such a fluorescent compound, of primary FCC ( $p$ FCC) (fig. 1), indeed confirmed it to be a chlorophyll catabolite [13]. At the same time the structure of $p$ FCC suggested it to be the direct ('primary') product of an elusive precursor that would be colored red $[1,13]$. The hypothetical red chlorophyll catabolite was prepared by chemical synthesis [14], and its intermediary role as the elusive red precursor of $p \mathrm{FCC}$ could be confirmed (fig. 1) $[1,3,15]$.

Typical natural FCCs do not accumulate as they convert to NCCs rapidly under physiological conditions. When $p$ FCC or its natural epimer, epi-pFCC [16], were exposed to slightly acidic conditions, these two FCCs were completely converted to a specific NCC each $[17,18]$. This thermodynamically favored, stereoselective chemical isomerization depended critically on the presence of the free propionic acid function of the $p$ FCCs and it was inhibited in the related (synthetic) methyl esters of the $p$ FCCs [18]. The isomerization of natural FCCs to NCCs was thus suggested to occur spontaneously in the acidic milieu of the vacuoles, and without participation of an enzyme $[3,5,17]$, as was, in fact, considered earlier, when the first structure of a $p F C C$ was elucidated [13]. 


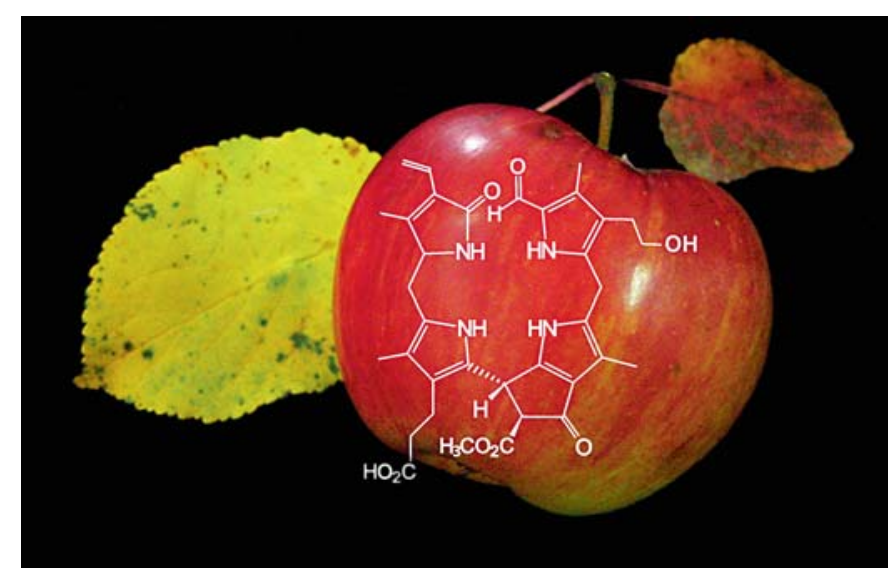

Fig. 2. A picture of a ripe apple and of senescent yellow- and redcolored leaves. The chemical formula represents the most abundant NCC (Ms-NCC-2) detected in both ripening apples and senescent leaves of an apple tree.

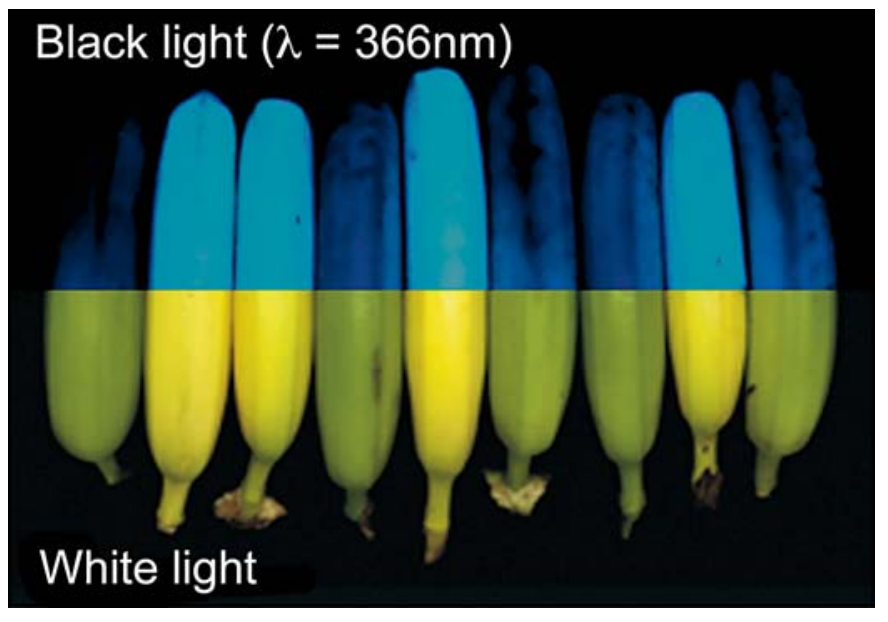

Fig. 3. Yellow bananas are blue luminescent. Yellow ripe and green unripe bananas are pictured under white light or UV light at 366 nm.
Fig. 4. a Luminescence spectra of intact ripened bananas, when greenish (green line), bright yellow (blue line) and brownyellow (black line), and of Mc-FCC (in methanol, dashed red line), with excitation at $350 \mathrm{~nm}$ [7]. b Chemical formula of $\mathrm{Mc}$ FCC-56, the main FCC from peels of bananas (Musa cavendish) [7].

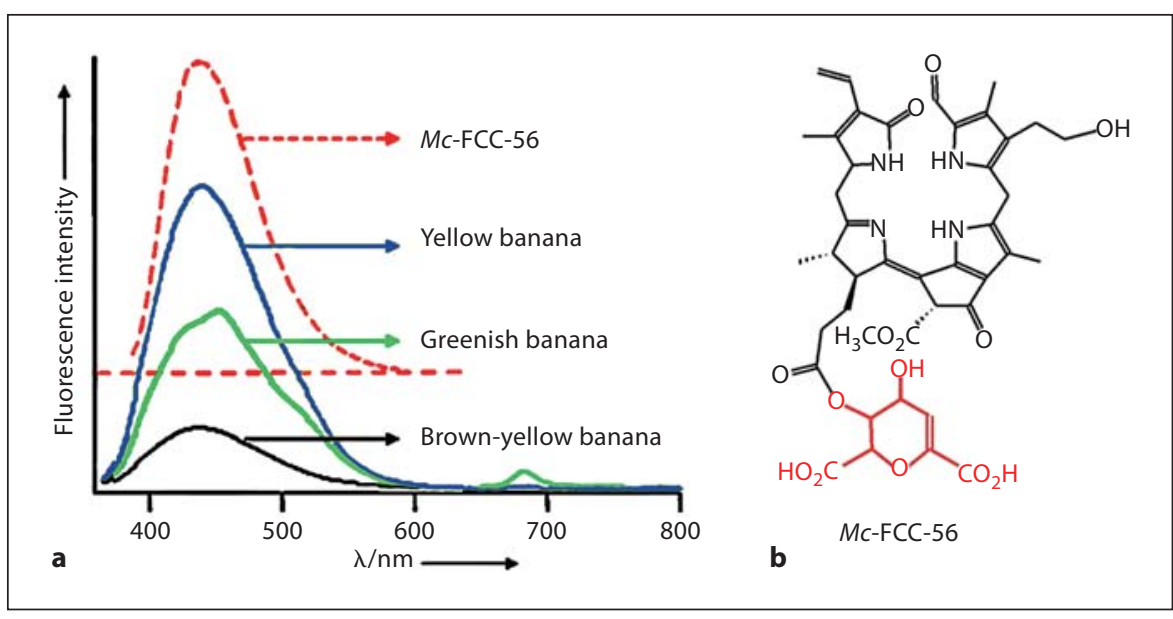

Structural Identification of Colorless Chlorophyll

Catabolites in Fruit

Common knowledge suggests the development of yellow and red colors during ripening of fruit as an indirect sign of the breakdown of chlorophyll (fig. 2). However, the remains of the green plant pigments in ripe fruit have until recently been unknown [9]. Analysis of fresh extracts of peels of ripe apples of the 'Golden Delicious' brand and of 'Williams' pears revealed the presence of two NCCs. The same two NCCs were also detected in senescent leaves of the two fruit trees (see formula shown in fig. 2) [9], suggesting a common biochemical path of chlorophyll breakdown in senescent leaves and in ripening fruit. NCCs were thus indicated to be the typical tetrapyrrolic remains of the chlorophylls in higher plants $[4,9]$.

\section{Blue Luminescence of Ripening Bananas}

The sweet 'dessert' banana (cavendish cultivar of Musa acuminata) is one of the most important fruits worldwide. Degreening is a clearly visible indicator to distinguish between delicious sweet and unripe harsh stages of bananas as well as of many other fruits. Surprisingly, the biochemical pathway of chlorophyll degradation in the 
Fig. 5. Chlorophyll breakdown in banana peels. The 'persistent' FCCs Mc-FCC-56 and $M c$-FCC-49 are proposed to be formed from $M c$-FCC- 64 by enzyme-catalyzed esterification followed by glucosylation [8].

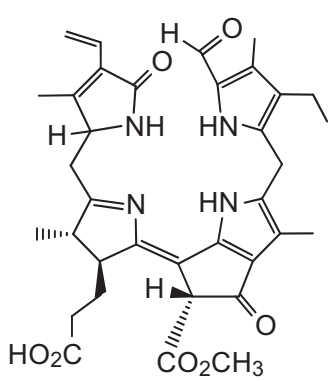

$p F C C$

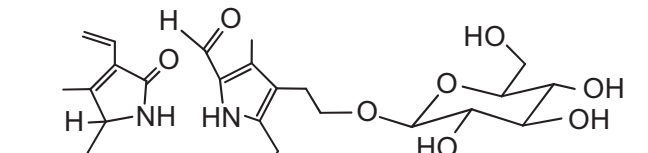

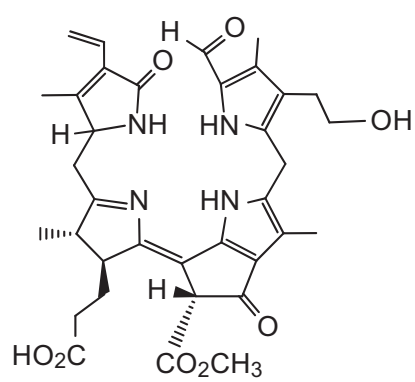

sFCC (Mc-FCC-64)
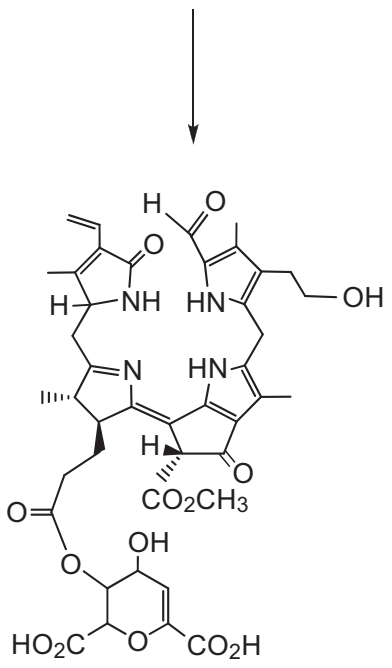

Mc-FCC-56 yellowing peel of bananas differs from that in ripening apples and pears [7-9]. Instead of NCCs 'chemically stabilized' fluorescent catabolites ('persistent' FCCs) occur in a large variety and accumulate in the peels of freshly ripe (yellow) bananas. As depicted in figure 3, the accumulation of FCCs in the outer regions of the peel causes yellow bananas to glow blue, when observed under UV light (at $366 \mathrm{~nm}$ ). The natural luminescence shows an emission maximum at $447 \mathrm{~nm}$. Its intensity is highest for fresh ripe, bright yellow bananas and decreases during the further aging process of the fruit [see fig. 4 in ref. 7]. Intact bananas and extracts of yellow banana peels, as well as solutions of purified FCCs, all showed similar fluorescence behavior (fig. 4a), suggesting FCCs as the source of the blue glow [5, 7]. As strongly fluorescing compounds, FCCs are also easily spotted using chromatographic analysis in combination with fluorescence detection.
Spectroscopic structural analysis of FCCs in yellow banana peels revealed their unusual structures and the chemical basis for their 'stabilization' [7]. The most abundant FCC in bright yellow banana peels, $M c$-FCC-56, was found to be esterified by a daucyl group (fig. 4 , the daucic acid moiety is highlighted in red). Chlorophyll breakdown in bananas thus deviates from that revealed earlier in senescent leaves (fig. 5). Accumulation of FCCs in yellow banana peels can be rationalized by chemical arguments: the lack of a free propionic acid side chain hinders the easily occurring acid-catalyzed conversion of typical FCCs to NCCs, and the esterified FCCs were thus classified as 'persistent' FCCs $[17,18]$. Clearly, this biosynthetic stabilization of FCCs against isomerization to NCCs and the resulting blue luminescence of the ripening banana fruit are striking new features of chlorophyll breakdown $[7,8]$. 
The stunning results with banana fruit induced further studies with senescent leaves of bananas (M. acuminata). As could be observed under UV light, banana leaves also showed blue luminescence, which was again found to be due to accumulation of FCCs. Indeed, the FCCs from degreened banana leaves ( $M a$-FCCs) clearly differed from their relatives in the fruit peels (Mc-FCCs), although they were identified again as 'persistent' FCCs, i.e. FCCs with a (complex) esterification of their propionate function (fig. 5) [19]. These results now contrast with the earlier notion of a common path of chlorophyll breakdown in senescent leaves and ripening fruit [9].

\section{Blue Halos of Cell Death in Aging Bananas}

'Senescence-associated' dark spots appear on the peel of bananas during a short period of aging that follows upon the ripening and yellowing, as typical signs of postharvest deterioration [20, 21] (fig. 5). The diagnostic senescence-associated spots appear on the peel accompanied by a fade-out of the natural blue luminescence [7]. At the same time remarkable intense, blue luminescent rings begin to develop around these dark spots, which are sections of the peel containing dead cells (fig. 6) [8]. Peels of bananas are very sensitive to physical damage of their surface, and the ripening process is also sensitive to lower temperatures. Only senescence-associated dark spots are surrounded by blue rings, and are thus diagnostic visual signs of banana overripening [8]. In contrast, dark features due to mechanical damage to the surface do not show the formation of fluorescent areas (fig. 6).

In vivo fluorescence analysis of these halo-like rings (fig. 6) suggested the presence of fluorescing chlorophyll catabolites due to a typical fluorescence emission maximum at $447 \mathrm{~nm}$, similar to that of isolated FCCs. Quantification using HPLC analysis verified this unexpected accumulation of fluorescent chlorophyll degradation products. Elevated levels of FCCs were found within the bright fluorescent areas, whereas considerably lower FCC levels were detected in dull yellow areas. In the dark spots the levels of FCCs were still smaller, all consistent with quantitative fluorescence measurements with intact bananas [7]. Structure elucidation revealed the main contributor to this remarkable blue luminescence to be another 'persistent' FCC, called Mc-FCC-49 (fig. 6, inset). $M c$-FCC-49 is the product of a further enzyme-catalyzed 'hypermodification' of $M c$-FCC-56, the major fluorescent catabolite from the yellow banana peel (fig. 5, 6).

Dark senescence-associated spots are known to originate from near the stomata on the ripening banana peel [22], and are presumed to arise from spontaneous oxida-

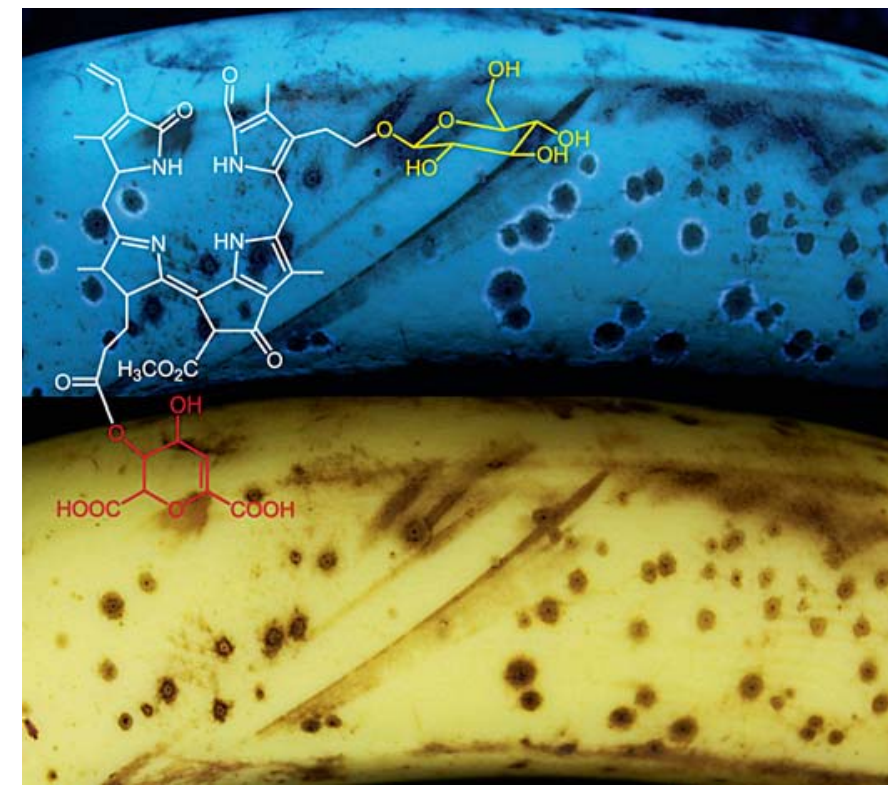

Fig. 6. Typical signs of postharvest deterioration of a banana peel observed under 366-nm UV light (top) and white light (bottom). Senescence-associated dark spots exhibit typical 'blue luminescent halos'. In contrast, mechanical damage causes dark surface areas that have no 'halos'. The chemical formula depicts the 'hypermodified' FCC Mc-FCC-49, which accumulates in 'blue luminescent halos'. The propionate ester group is marked in red, while the glucoside moiety on ring $\mathrm{B}$ is highlighted in yellow.

tive processes [20]. Detailed microscopic analyses confirmed the presence of the cellular remains of stomata in the center of the 'dark' spots and revealed the blue rings to mark an area on the peel surface in which the cells were still intact and 'alive', but to be considered 'senescent' [8].

Emergence and disappearance of blue halos could be studied noninvasively, and in time- and 2-dimensional space-resolved fashion by in vivo fluorescence measurements (fig. 7) [8]. Indeed, the selective accumulation of specifically 'hypermodified' FCCs suggests a physiological benefit from the prolonged persistence of these linear tetrapyrroles and calls for further investigations of their fate. On the one hand, the phenomenon might be of relevance for helping to inhibit the decline of vital functions of the fruit [23]. Hence it may prove to be a helpful noninvasive, molecular tool to study underlying cellular aging processes. On the other hand, fruit-eating animals could have learned through survival pressure [24] to see the blue bioluminescence of bananas as a noticeable signal of fruit ripeness. 
Fig. 7. a Typical experimental setup for measuring 2-dimensionally resolved in vivo fluorescence of plant tissue. The fluorescence probe is fixed; a motor-driven mechanical xy-stage moves the banana. b Luminescence map (in false colors) of a peel area surrounding a dark spot (luminescence detected at $450 \mathrm{~nm}$, excitation at $350 \mathrm{~nm})$.
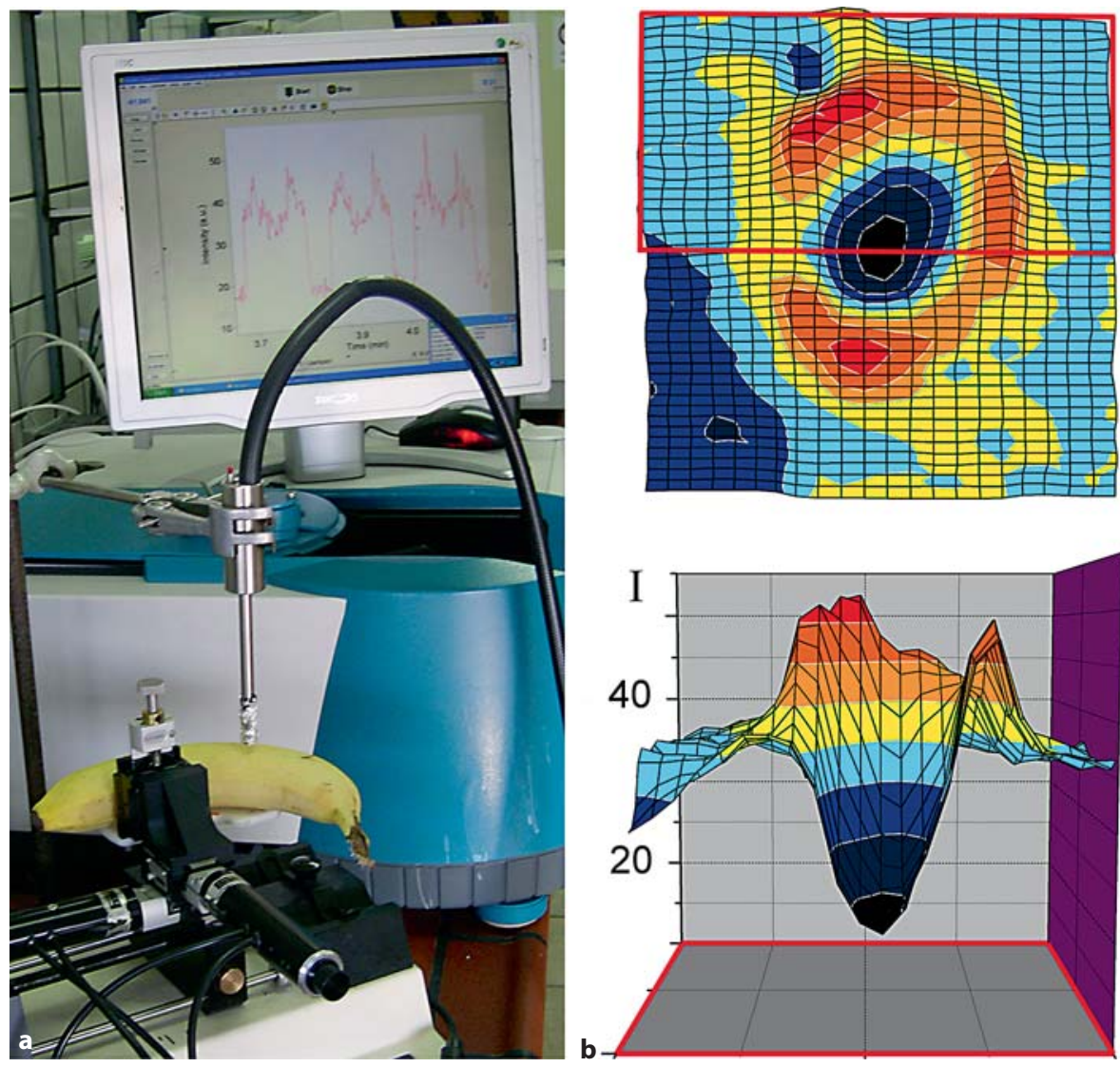

\section{Chlorophyll Catabolites as Antioxidants}

Chlorophyll degradation was, first of all, interpreted as a detoxification process [6], a part of a recycling strategy of higher plants to recover essential minerals (such as magnesium and reduced forms of nitrogen). Moreover, a recent investigation of chlorophyll catabolites in fruit [9] revealed remarkable antioxidant properties of NCCs. One of the 'fruit' NCCs found in ripening apples and pears [9] was tested in a standard auto-oxidation experiment designed for the analysis of bilirubin [25]: the rate of formation of hydroperoxides of linoleic acid was significantly reduced in the presence of the NCC. The (antioxidative) peroxy-radical scavenging effect of the tested NCC (for the formula see fig. 2) was only slightly inferior to that of bilirubin [25]. These results were of particular interest to us, because NCCs are structurally related to the tetrapyrrolic heme breakdown product bilirubin and other heme-derived natural linear tetrapyrroles (fig. 8) [26]. Bilirubin was shown to be an antioxidant [25] and a cytoprotective component, relevant in the reduction of coronary heart diseases, retinal damage and cancer mor-

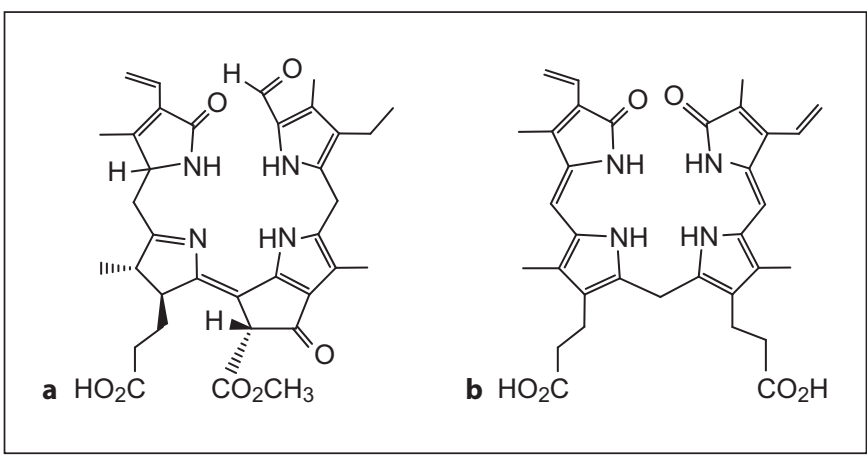

Fig. 8. Tetrapyrrolic chlorophyll and heme degradation products are related structurally. Formulae of the NCC $M s-\mathrm{NCC}-2$ from a ripe apple (a) and of the heme catabolite bilirubin (b).

tality [27]. The availability of the NCCs in plant-derived nutrition, as now documented for apples and pears, calls for their consideration as being of physiological interest in humans (and higher animals), and not as mere degradation products of the phototoxic green plant pigments. 
These findings may even give a new twist to the meaning of the old saying 'an apple a day keeps the doctor away' $[4,5]$.

\section{Conclusions}

Chlorophyll breakdown provides a visually pleasing sign of ripening and of senescence in bananas $[7,8]$. It has been apostrophized as a necessary 'detoxification process' of the green plant pigment during senescence [6]. This worldwide controlled degradation of the motor of the plant's basic metabolism is an intriguing phenomenon. One may specifically wonder how metabolism in the ripening fruit may continue to function (nearly) without chlorophyll. Of course, the soft fruit eventually undergoes a further transition to senescence and cell death. However, the degreened tetrapyrrolic remains of the chlorophylls are distantly related to the heme-derived bilins, and chlorophyll catabolites may have relevant physiological roles in bananas and other fruits. Their presence in the nutrition of humans and frugivorous animals may also call for interest in their broader (physiological) effects. In addition, FCCs are luminescent molecular markers of ripening and cell death that may be useful for noninvasive in situ analysis of (fruit) ripening and senescence in higher plants.

\section{Acknowledgments}

We would like to thank Simone Moser (Innsbruck) for her excellent contributions, Stefan Hörtensteiner (Zürich), Steffen Jockusch, Nicholas Turro (New York), Andreas Holzinger and Cornelius Lütz (Innsbruck) for their collaborations. Our work was generously supported by the Austrian Science Foundation (FWF, recent projects $\mathrm{P}-19596$ and L-472).

\section{References}

$>1$ Kräutler B, Matile P: Solving the riddle of $>10$ Matile P, Hörtensteiner S, Thomas H, Kräutler chlorophyll breakdown. Acc Chem Res 1999; 32: $35-43$

2 Kräutler B, Jaun B, Bortlik K, Schellenberg M, Matile P: On the enigma of chlorophyll degradation - the constitution of a secoporphinoid catabolite. Angew Chem Int Ed Engl 1991; 30: 1315-1318.

3 Kräutler B, Hörtensteiner S: Chlorophyll catabolites and the biochemistry of chlorophyll breakdown; in Grimm B, Porra R, Rüdiger W, Scheer H (eds): Chlorophylls and Bacteriochlorophylls. Dordrecht, Springer, 2006, vol 25, pp 237-260.

4 Kräutler B: Chlorophyll breakdown and chlorophyll catabolites in leaves and fruit. Photochem Photobiol Sci 2008; 7: 1114-1120.

5 Moser S, Müller T, Oberhuber M, Kräutler B: Chlorophyll catabolites - chemical and structural footprints of a fascinating biological phenomenon. Eur J Org Chem 2009; 1: 3.

6 Hörtensteiner S, Lee DW: Chlorophyll catabolism and leaf coloration; in Gan S (ed): Senescence Processes in Plants. Oxford, Blackwell Publisher, 2007, pp 12-38.

7 Moser S, Müller T, Ebert MO, Jockusch S, Turro NJ, Kräutler B: Blue luminescence of ripening bananas. Angew Chem Int Ed 2008; 47: 8954-8957.

8 Moser S, Müller T, Holzinger A, Lütz C, Jockusch S, Turro NJ, Kräutler B: Fluorescent chlorophyll catabolites in bananas light up blue halos of cell death. Proc Natl Acad Sci USA 2009; 106: 15538-15542.

9 Müller T, Ulrich M, Ongania KH, Kräutler B: Colourless tetrapyrrolic chlorophyll catabolites found in ripening fruit are effective antioxidants. Angew Chem Int Ed 2007; 46: 8699 8702 .
$\mathrm{B}$ : Chlorophyll breakdown in senescent leaves. Plant Physiol 1996; 112: 1403-1409.

11 Matile P, Ginsburg S, Schellenberg M, Thomas $\mathrm{H}$ : Catabolites of chlorophyll in senescing barley leaves are localized in the vacuoles of mesophyll-cells. Proc Natl Acad Sci USA 1988; 85: 9529-9532.

12 Kräutler B: Chlorophyll breakdown and chlorophyll catabolites; in Kadish KM, Smith KM, Guilard R (eds): The Porphyrin Handbook. Oxford, Elsevier Science, 2003, vol 13, pp 183 209.

-13 Mühlecker W, Ongania KH, Kräutler B, Matile P, Hörtensteiner S: Tracking down chlorophyll breakdown in plants: elucidation of the constitution of a 'fluorescent' chlorophyll catabolite. Angew Chem Int Ed 1997; 36: 401-404.

14 Kräutler B, Mühlecker W, Anderl M, Gerlach B: Breakdown of chlorophyll: partial synthesis of a putative intermediary catabolite. Helv Chim Acta 1997; 80: 1355-1362.

15 Rodoni S, Mühlecker W, Anderl M, Kräutler B, Moser D, Thomas H, Matile P, Hörtensteiner S: Chlorophyll breakdown in senescent chloroplasts. Cleavage of pheophorbide $a$ in two enzymic steps. Plant Physiol 1997; 115: 669-676.

16 Mühlecker W, Kräutler B, Moser D, Matile P, Hörtensteiner S: Breakdown of chlorophyll: a fluorescent chlorophyll catabolite from sweet pepper (Capsicum annuum). Helv Chim Acta 2000; 83: 278-286

7 Oberhuber M, Berghold J, Breuker K, Hörtensteiner S, Kräutler B: Breakdown of chlorophyll: a nonenzymatic reaction accounts for chlorophyll catabolites. Proc Natl Acad Sci USA 2003; 100: 6910-6915. the formation of the colorless 'nonfluorescent'
18 Oberhuber M, Berghold J, Kräutler B: Chlorophyll breakdown by a biomimetic route. Angew Chem Int Ed 2008; 47: 3057-3061.

19 Banala S, Moser S, Müller T, Kreutz C, Holzinger A, Lütz C, Kräutler B: Hypermodified fluorescent chlorophyll catabolites - source of blue luminescence in senescent leaves. Angew Chem Int Ed 2010; 49: 5174-5177.

20 Choehom R, Ketsa S, van Doorn WG: Senescent spotting of banana peel is inhibited by modified atmosphere packaging. Postharvest Biol Technol 2004; 31: 167-175.

21 Mendoza F, Aguilera JM: Application of image analysis for classification of ripening bananas. J Food Sci 2004; 69:E471-E477.

22 Romphophak T, Ueda Y, Terai H, Abe K: Study of senescent spotting of banana peel. Food Preservation Sci 2005; 31: 55-60.

23 Matile P: Senescence and cell death in plant development: chloroplast senescence and its regulation; in Aro AM, Andersson B (eds): Regulation of Photosynthesis. Dordrecht, Kluwer Academic Publisher, 2001, pp 277296.

24 Sumner P, Mollon JD: Chromaticity as a signal of ripeness in fruits taken by primates. J Exp Biol 2000; 203: 1987-2000.

25 Stocker R, Yamamoto Y, McDonagh AF, Glazer AN, Ames BN: Bilirubin is an antioxidant of possible physiological importance. Science 1987; 235: 1043-1046.

26 Falk H: Chemistry of Linear Oligopyrroles and Bile Pigments. Vienna, Springer, 1989.

27 Baranano DE, Rao M, Ferris CD, Snyder SH: Biliverdin reductase: a major physiologic cytoprotectant. Proc Natl Acad Sci USA 2002; 99: 16093-16098. 